\title{
Calcification and airway stenosis in a child with chondrodysplasia calcificans punctata
}

\author{
Pierre Goussard, ${ }^{1}$ Savvas Andronikou, ${ }^{2}$ Namakula S Semakula-Katende, ${ }^{3}$ Robert Gie ${ }^{1}$
}

${ }^{1}$ Departments of Paediatrics and Child Health, Faculty of Medicine and Health Sciences, Stellenbosch University, and Tygerberg Children's Hospital, Cape Town, South Africa ${ }^{2}$ Department of Radiology, University of the

Witwatersrand, Johannesburg, South Africa

${ }^{3}$ Department of Radiology, Faculty of Health Sciences, University of the Witwatersrand, Johannesburg, South Africa

\section{Correspondence to Dr Pierre Goussard, pgouss@sun.ac.za}

Accepted 2 September 2014

\section{CrossMark}

\begin{tabular}{|l|}
\hline To cite: Goussard P, \\
Andronikou S, Semakula- \\
Katende NS, et al. BMJ Case \\
Rep Published online: \\
[please include Day Month \\
Year] doi:10.1136/bcr-2014- \\
205087 \\
\hline
\end{tabular}

\section{SUMMARY}

Calcification of the airways is rarely seen in children. A male baby was born at 34 weeks with severe respiratory distress. Intubation was difficult with severe hypercarbia after intubation. Chest radiography demonstrated calcification in the tracheobronchial tree and this was confirmed with Chest CT scan. Flexible bronchoscopy confirmed long-segment funnel tracheal stenosis with visible calcifications in the trachea and bronchi. Chondrodysplasia punctata was diagnosed based on the clinical and radiological findings.

\section{BACKGROUND}

Calcification of the airways as seen on imaging is rare in children. ${ }^{1-3}$ It can be idiopathic, ${ }^{1}$ or from known causes. Genetic conditions such as X linked recessive chondrodysplasia calcificans punctata $^{2-4}$ (CCP) must be considered when there are clinical stigmata. Imaging suggests the diagnosis and can demonstrate airway complications.

\section{CASE PRESENTATION}

A male baby born at 34 weeks and weighing $2.541 \mathrm{~kg}$ had apgars of 3, 5 and 5. At 1-day-of-age he presented with severe respiratory distress. Intubation proved difficult but, once achieved, the partial pressure of carbon dioxide was extremely high $(18 \mathrm{kPa})$. On examination the baby had mid-face hypoplasia, hypoplastic fingernails and short limbs.

Chest X-ray (CXR) demonstrated calcification in the tracheobronchial tree (figure 1). There was bilateral, symmetrical, diffuse granularity to the lungs with loss of the cardiac and diaphragmatic margins consistent with respiratory distress syndrome in a premature neonate. Humeral epiphyses were not well visualised on CXR because of the gestational age at birth. Cardiac echography was normal. CT of the chest with coronal reformatting confirmed the extensive tracheobronchial cartilage calcification (figure 2).

Flexible bronchoscopy confirmed long-segment funnel tracheal stenosis (broader at the top than bottom) with visible calcifications in the trachea and bronchi.

The final assessment was severe tracheal stenosis with calcified tracheal rings in a child with suspected X linked recessive form. Genetic studies for confirmation of diagnosis have not been attempted as this facility is not available in this country.

\section{INVESTIGATIONS}

Genetic studies for confirmation of diagnosis have not been attempted as this facility is not available in this country.

\section{OUTCOME AND FOLLOW-UP}

Owing to the poor prognosis it was opted to withdraw treatment after discussing it with the parents.

\section{DISCUSSION}

Calcification of the airways in children is rare ${ }^{1-3}$ and may either be physiological (more common in children over 13 years of age), ${ }^{1}$ idiopathic (without a cause) ${ }^{1}$ or may be due to known conditions such as congenital cardiac disease (eg, ventricular septal defect, patent ductus arteriosus, mitral valve insufficiency or coarctation) ${ }^{1}$ and warfarin embryopathy. ${ }^{4}$ Syndromal causes include Keutel syndrome, ${ }^{1}{ }^{2}$ a rare disorder of glutamic acid protein modification, which can cause prominent, diffuse calcification of the epiglottis, nose, larynx, tracheobronchial tree and cerebrum. ${ }^{2}$ This syndrome may be associated with maternal systemic lupus erythematosus or may be congenital. ${ }^{2}$

$\mathrm{CCP}$ is a rare congenital syndrome caused by a peroxisomal dysfunction that displays punctate calcific depositions ('stippling') in areas of enchondral bone formation. This leads to erratic cartilage calcification during growth resulting in bone and skin lesions, cataracts and cardiac malformations. ${ }^{3}$ The $\mathrm{X}$ linked recessive form, described only in boys (brachytelephalangic chondrodysplasia punctata) is characterised by facial dysmorphism with a deeply set nose and chondrodysplasia punctata. It involves multiple

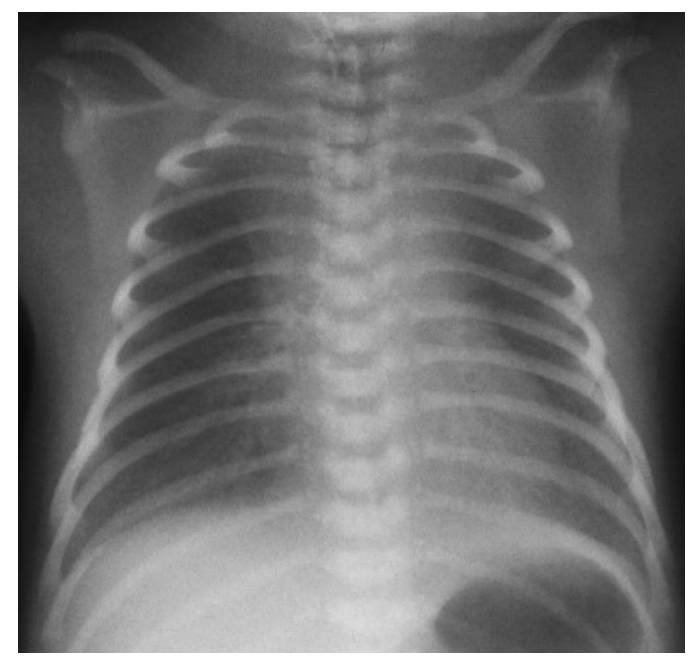

Figure 1 Chest X-ray demonstrates calcification of the trachea and both main bronchi (arrows). There is bilateral, symmetrical, diffuse granularity to the lungs with loss of the cardiac and diaphragmatic margins consistent with respiratory distress syndrome in this premature neonate. There are no features of congenital heart disease. 
Figure 2 CT scan of the chest: (A) axial CT at the level of the trachea confirming circumferential tracheal calcification; (B) axial CT at the level of the main bronchi demonstrating partial calcification involving predominately the anterior aspect of the bronchi and (C) coronal CT reformatting demonstrating extensive tracheobronchial calcifications of the airways.
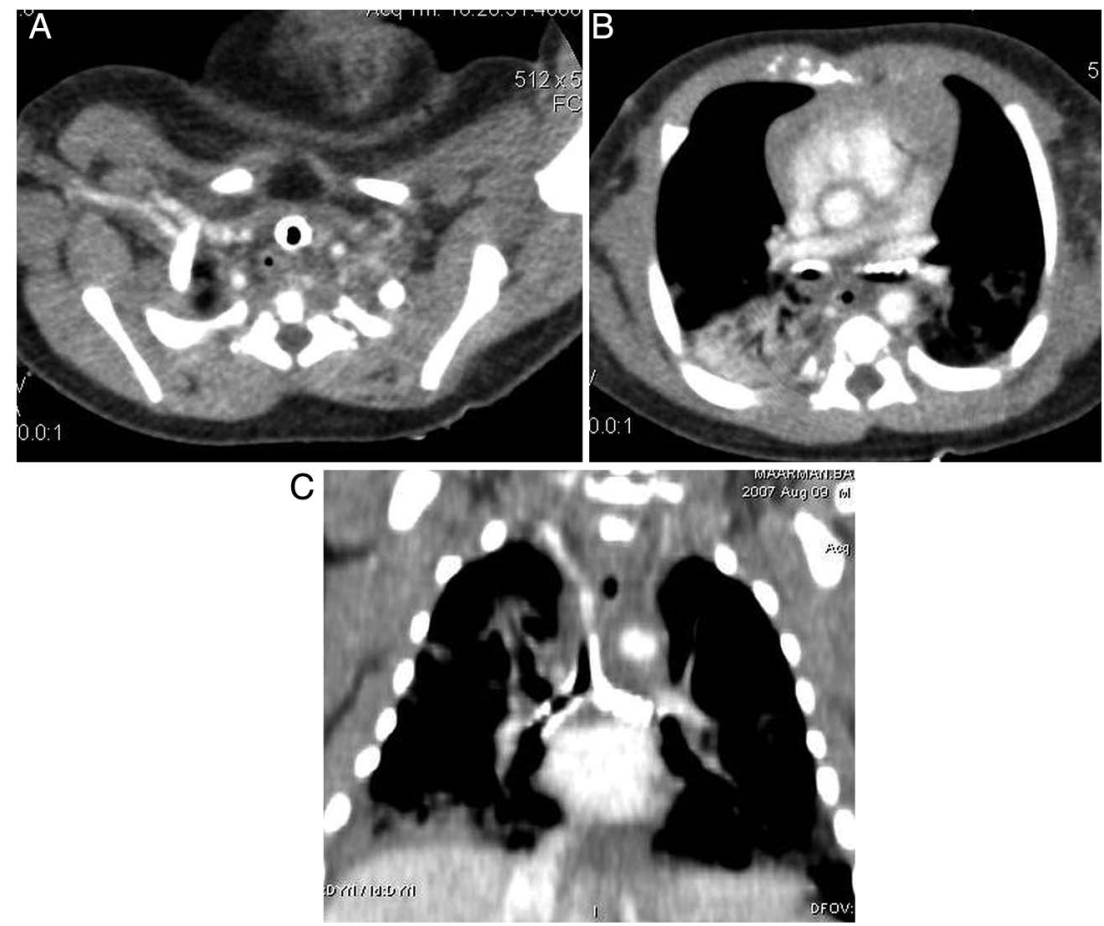

cartilaginous structures, particularly the tarsal bones and airway cartilage (which disappear by age 2-3 years), and demonstrates distinctive marked osseous changes with shortening of the distal phalanges of the hands and feet, ${ }^{5}$ as noted in our patient. Radiological manifestations typically include chondrodysplasia, epiphysial stippling, punctate calcification of cartilage (including the airway), distal phalangeal hypoplasia and nasal/mid-face hypoplasia. ${ }^{2}$ Tracheal stenosis and fibrosis may result from difficult intubation procedures, ${ }^{3}$ as was the situation in our patient.

In summary, clinical and imaging findings are described for a newborn with respiratory distress, calcification of the airway on imaging and clinical stigmata of $\mathrm{X}$ linked chondrodysplasia

\section{Learning points}

- Calcification of the airways as seen on imaging is rare in children.

- Chondrodysplasia calcificans punctata displays punctate calcific depositions ('stippling') in areas of enchondral bone formation.

- Bronchoscopy is important to exclude tracheal stenosis. punctata, highlighting the presence of tracheal stenosis with a terminal outcome. Imaging is important as it can demonstrate airway complications allowing for earlier intervention in an attempt to improve the patient's outcome.

Contributors $P G$ and RG were involved in the patient management. SA and NSSK were responsible for the radiology. PG and SA prepared the manuscript with input from the other two coauthors.

Competing interests None.

Patient consent Parental/guardian consent obtained.

Provenance and peer review Not commissioned; externally peer reviewed.

\section{REFERENCES}

1 Ceyha M, Nural M, Elmali M, et al. Idiopathic isolated laryngotracheobronchial cartilage calcification in a child. Clin Imaging 2008;32:51-3.

2 Mundinger G, Weiss C, Fishman E. Severe tracheobronchial stenosis and cervical vertebral subluxation in X-linked recessive chondrodysplasia punctata. Pediatr Radiol 2009;39:625-8.

3 Karoutsos S, Lansade A, Terrier G, et al. Chondrodysplasia punctata and subglottic stenosis. Anaesth Analg 1999;89:1322-3.

4 Joshi A, Berdon W, Ruzal-Shapiro C, et al. CT detection of tracheobronchial calcification in an 18-year-old on maintenance warfarin sodium therapy: cause and effect? AJR Am J Roentgenol 2000;3:921-2.

5 Herman T, McAlister W, Lee B. Brachytelephalangic chondrodysplasia punctate with marked cervical stenosis and cord compression: report of two cases. Pediatric Radiology 2002;32:452-6.

Copyright 2014 BMJ Publishing Group. All rights reserved. For permission to reuse any of this content visit

http://group.bmj.com/group/rights-licensing/permissions.

BMJ Case Report Fellows may re-use this article for personal use and teaching without any further permission.

Become a Fellow of BMJ Case Reports today and you can:

- Submit as many cases as you like

- Enjoy fast sympathetic peer review and rapid publication of accepted articles

- Access all the published articles

- Re-use any of the published material for personal use and teaching without further permission

For information on Institutional Fellowships contact consortiasales@bmjgroup.com

Visit casereports.bmj.com for more articles like this and to become a Fellow 